\title{
Comparison of the Strength of Midship Structures with and without Margin Plate
}

\author{
Rosmani $^{\mathrm{a}, *}$, Andi Ardianti ${ }^{\mathrm{b}}$, Hariyono ${ }^{\mathrm{c}}$, Ganding Sitepu ${ }^{\mathrm{d}}$, Hamzah $^{\mathrm{e}}$

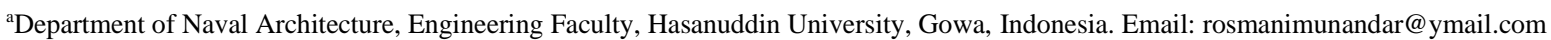 \\ bDepartment of Naval Architecture, Engineering Faculty, Hasanuddin University, Gowa, Indonesia. Email: aardianti@gmail.com \\ 'Department of Naval Architecture, Engineering Faculty, Hasanuddin University, Gowa, Indonesia. Email: hariyono.ismail07@gmail.com \\ ${ }^{\mathrm{d}}$ Department of Naval Architecture, Engineering Faculty, Hasanuddin University, Gowa, Indonesia. Email: g.sitepu@unhas.ac.id \\ e Department of Naval Architecture, Engineering Faculty, Hasanuddin University, Gowa, Indonesia. Email: anca_naval99@yahoo.com
}

\begin{abstract}
Margin plate is a part of bottom construction that joint the floor and frame construction of the ship, so the inner bottom plate will be installed cut off on the margin plate. Lately, the bottom construction of the ship tends not to use the margin plate. The ship is currently built with an inner bottom plate continuously from the left side to the right side of the ship. This study aims to determine the transversal and longitudinal strength ratio of ships with and without margin plate. The analysis was carried out by using Finite Element Method socalled ANSYS ${ }^{\mathrm{TM}}$. The result shows if the load varied $0.2 \mathrm{x}$ maximum load on the calculation of the transverse strength of the ship, the stress value on the ship model with a margin plate was $9.6242\left(\mathrm{~N} / \mathrm{mm}^{2}\right)$ and on the ship model without margin plate was $8.4739\left(\mathrm{~N} / \mathrm{mm}^{2}\right)$ under conditions $100 \%$. The results of the comparison due to bottom load averaged $15.82 \%$. The difference in stress due to the effect of deck loads was an average of $13.49 \%$ while the effect of side loads was on average $8.74 \%$. The longitudinal strength of the ship was also varied of every increase of $0.2 \mathrm{x}$ maximum moment with a review point of meeting between the bottom plate and bilge plate for the ship model without margin plates using the Multi-Point Constraint (MPC) method looking for results in sagging conditions of 12,443 $\left(\mathrm{N} / \mathrm{mm}^{2}\right)$ and the hogging condition was $-11.045\left(\mathrm{~N} / \mathrm{mm}^{2}\right)$ at $100 \% \mathrm{x}$ maximum moment load conditions. So that the ship model with a margin plate sagging condition was $23,189\left(\mathrm{~N} / \mathrm{mm}^{2}\right)$ and hagging condition was $-20,585\left(\mathrm{~N} / \mathrm{mm}^{2}\right)$. The results showed the stress that occurred in the ship model without using margin plate was better to withstand the transverse and longitudinal strength of the ship compared to the ship model with the margin plate.
\end{abstract}

Keywords: Load; margin plate; moment, stress; multi-point constraint (MPC)

\section{Introduction}

The strength of the ship construction is one of the technical aspects that also affects the level of ship safety in both calm and wavy sea conditions [1]. Recently, the ships building process with sophisticated technology can be completed quickly compared to the past. Thus the considerations in designing the ship construction are also very concerned, especially the strength of the ship, both transverse and longitudinal strength of the ship. One difference in the design of the current ship structure is the use of margin plates, now it is very rare to find ship construction using margin plate. If the construction of a ship is designed without margin plate, the inner bottom plate can be installed continuously from the left side to the right side of the ship [2] as shown in Fig. 1.

This research is related to the tendency of shipbuilding with a bottom structure without a margin plate which can affect the strength or affect the stress distribution in the construction components on the double bottom of the ship.
Therefore, it is necessary to examine the stress distribution or the difference in the response of the vessel structure between a margin plate and without a margin plate. This study aims to determine the ratio of transverse and longitudinal strengths of ships with and without margin plates. The analysis was done using the finite element method with the help of software ANSYS ${ }^{\mathrm{TM}}$.

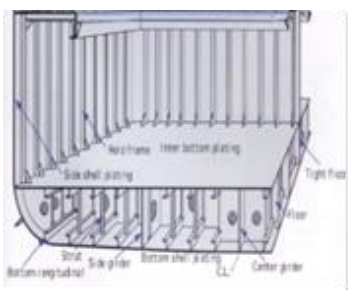

(a)

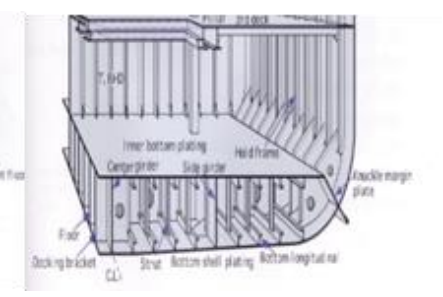

(b)
Figure 1. Differences in Midship construction without using a margin plate (a) and construction using a margin plate (b)

${ }^{*}$ Corresponding author. Tel.: +62 813-4227-6450

Jalan Poros Malino km. 6 Bontomarannu

Gowa, Indonesia, 92171 


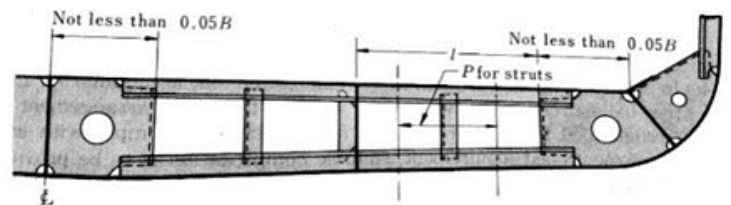

Figure 2. Open floor stipulates the distance of the plate margin from the supporting plate

The installation of double bottom can increase the safety of the ship as well as a ballast tank, if the ship collided with the reef and the outside of the bottom plate is torn, the watertight inner bottom plate will limit/protect the cargo from damage caused by water [3].

Based on Fig. 2, it can be seen that the bottom construction using a margin plate with the support plate distance to the edge of the edge plate is $0.05 \mathrm{~B}$ [4]. The inner bottom plate mounted on the top of the tank is continued to the side of the ship at a distance of not less than $1 / 10$ of the height measured from the baseline to the inner bottom plate [5]. The edge plate construction works as a longitudinal beam, as support for bilge which is mounted perpendicular to the bilge plate and is welded to the bilge floor and knee. The width and thickness will be the same as the length of the ship where the thickness depends on the width of the vessel, but in practice the same thickness of the center support plate. Edge plates can also be cut by the knee or cut into each other [3].

There are two main types of framing systems; namely the transverse framing system and the longitudinal framing system. Of these two main systems, the combination/mixed framing system is also known [6]. Loads acting on the ship such as loads on the deck, loads on the sides, and loads on the plinth. So it is clear that the main components of the ship's structure are the bottom structure, the side structure, and the deck structure. These loads may affect the local structure and must be taken into account in the design including Fig. 3. These loads consist of two parts, namely: 1) upward compressive force, and 2) hydrostatic force on the outer plane of the submerged hull. Gravity is the greatest downward force on the entire ship and its contents [1].

Either of classifying loads on ships is according to the structural level acting as some loads affect the structure i.e. only one of four levels such as hull girders, hull modules, major construction components, and local components [7]. This moment is caused due to the load due to wave conditions such as hogging and sagging conditions. In hogging conditions, the ship gets a pull force at the bottom and a compressive force on the deck of the ship. On the other hand, the sagging condition [8] can be seen in Fig. 4.

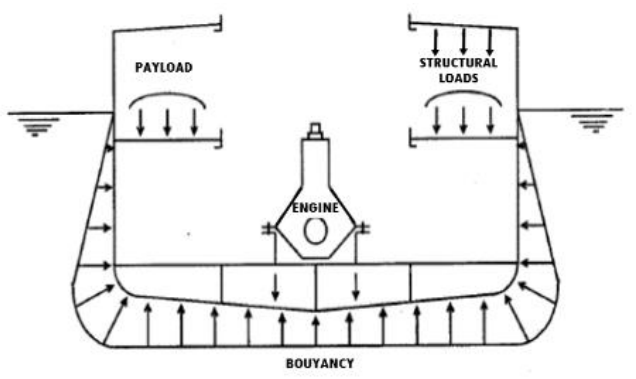

Figure 3. Load components on the hull

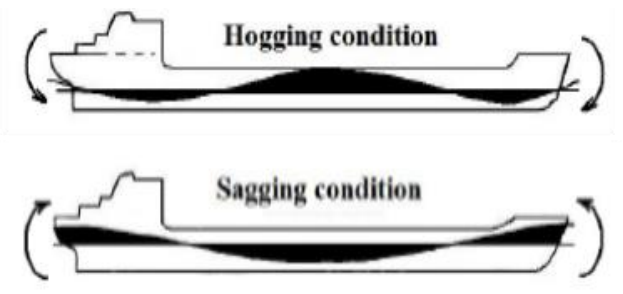

Figure 4. Hogging and sagging conditions

Finite Element Method is a numerical method used to solve technical problems and mathematical problems from a physical phenomenon. Types of technical and physicalmathematical problems that can be solved by the finite element method are structural and non-structural analysis. Types of structural analysis problems include stress, buckling and vibration analysis, while non-structure includes heat and mass transfer, fluid mechanics, and distribution of electric and magnetic potentials [9].

In a plane known to be a force, there will be two types of stresses that affect the plane. Generally, the three dimensions of stress elements are illustrated in Fig. 5. Three positive normal stress $\sigma_{x}, \sigma_{y}$ dan $\sigma_{z}$, there are 6 positive shear stress, $\tau_{x y,} \tau_{y x}, \tau_{y z}, \tau_{z y}, \tau_{z x}$, and $\tau_{x z}$, displayed to ensure static balance, as equation (1) applies [10].

$$
\tau_{x y}=\tau_{y x}, \quad \tau_{y z}=\tau_{z y}, \quad \tau_{z x}=\tau_{x z}
$$

The normal stress equation for the three-dimensional plane is [10] :

$$
\begin{aligned}
& \sigma_{x}=\frac{E}{(1+v)(1-2 v)}\left[\varepsilon_{x}(1+v)+v\left(\varepsilon_{y}+\varepsilon_{z}\right)\right] \\
& \sigma_{y}=\frac{E}{(1+v)(1-2 v)}\left[\varepsilon_{y}(1+v)+v\left(\varepsilon_{x}+\varepsilon_{z}\right)\right] \\
& \sigma_{z}=\frac{E}{(1+v)(1-2 v)}\left[\varepsilon_{z}(1+v)+v\left(\varepsilon_{x}+\varepsilon_{y}\right)\right]
\end{aligned}
$$

The strain is defined as the ratio between the increase in length or shortness of the rod with the initial size [11].

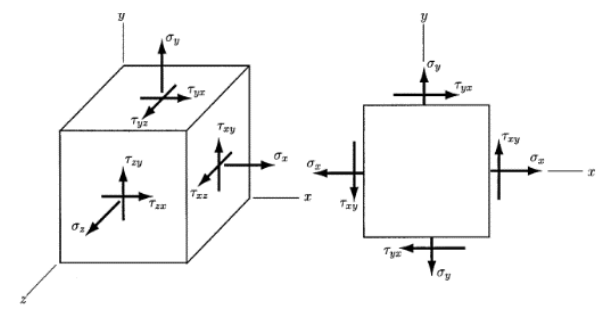

Description:

Figure 5. Stress acting on a plane

$\sigma_{x}:$ normal stress acting on the x plane

$\sigma_{y}:$ normal stress acting on the y plane

$\sigma_{z}$ : normal stress acting on the $\mathrm{z}$ plane

$\tau_{x y}$ : shear stress acting on the $\mathrm{x}$ normal plane in the $\mathrm{y}$ direction

$\tau_{x z}$ : shear stress acting on the $\mathrm{x}$ normal plane in the $\mathrm{z}$ direction

$\tau_{y x}$ : shear stress acting on the $\mathrm{y}$ normal plane in the $\mathrm{x}$ direction

$\tau_{y z}$ : shear stress acting on the y normal plane in the $\mathrm{z}$ direction 


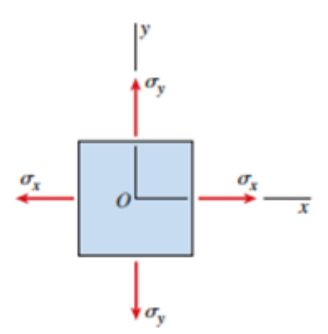

Figure 6. Biaxial tension system

The special case of biaxial stress (Fig. 6) occurs when in a structure axial loads act in two mutually perpendicular axes. We have $\tau_{\mathrm{xy}}=0$, so Hooke's law for plane stresses is simplified to [10]

$$
\begin{gathered}
\varepsilon_{x}=\frac{1}{E}\left(\sigma_{x}-v \sigma_{y}\right) \\
\varepsilon_{y}=\frac{1}{E}\left(\sigma_{y}-v \sigma_{x}\right) \\
\sigma_{x}=\frac{E}{1-v^{2}}\left(\varepsilon_{x}-v \varepsilon_{y}\right) \\
\sigma_{y}=\frac{E}{1-v^{2}}\left(\varepsilon_{y}-v \varepsilon_{x}\right)
\end{gathered}
$$

Furthermore, the triaxial stress system occurs if the stress acts in the three directions of the coordinate axes. If the material follows Hooke's law, we can obtain the relationship between normal stress and normal strain as in Fig. 7 [10].

The strain generated by the stresses $\sigma_{x}, \sigma_{y}$, and $\sigma_{z}$ acting independently to obtain the resulting strain. Thus, we easily arrive at the following equation for strain in triaxial stress [10].

$$
\begin{aligned}
& \varepsilon_{x}=\frac{\sigma_{x}}{E}-\frac{v}{E}\left(\sigma_{y}+\sigma_{z}\right) \\
& \varepsilon_{y}=\frac{\sigma_{y}}{E}-\frac{v}{E}\left(\sigma_{z}+\sigma_{x}\right) \\
& \varepsilon_{z}=\frac{\sigma_{z}}{E}-\frac{v}{E}\left(\sigma_{x}+\sigma_{y}\right)
\end{aligned}
$$

In this equation, the standard sign convention is used; that is, the tensile stress $\mathrm{s}$ and the extensional strain e are positive. The previous equation can be solved simultaneously for stress in terms of strain [10].

$$
\begin{aligned}
& \sigma_{x}=\frac{E}{(1+v)(-2 v)}\left[(1-v) \varepsilon_{x}+v\left(\varepsilon_{y}+\varepsilon_{z}\right)\right] \\
& \sigma_{y}=\frac{E}{(1+v)(-2 v)}\left[(1-v) \varepsilon_{y}+v\left(\varepsilon_{z}+\varepsilon_{x}\right)\right] \\
& \sigma_{z}=\frac{E}{(1+v)(-2 v)}\left[(1-v) \varepsilon_{z}+v\left(\varepsilon_{x}+\varepsilon_{y}\right)\right]
\end{aligned}
$$

The equation for a simple supported beam that is uniformly loaded is as follows [10]:

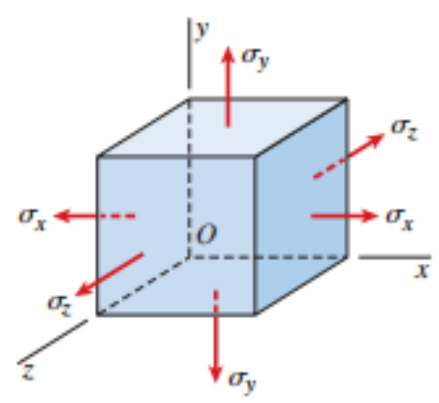

Figure 7. Biaxial tension system

maximum deflection

$$
\Delta=\frac{S W L^{4}}{384} E I
$$

deflection permit

$$
\begin{gathered}
\Delta_{\text {permit }}=\frac{S W L^{4}}{384} \text { or } \\
\Delta_{\text {permit }}=\frac{5(360) S W L^{4}}{384 E L}
\end{gathered}
$$

where,

E : Modulus elastis $\left(\mathrm{N} / \mathrm{mm}^{2}\right)$

I : Momen inersia $\left(\mathrm{m}^{4}\right)$

W : Load equivalent $(\mathrm{N} / \mathrm{mm})$

$\mathrm{L} \quad$ : Length deflection (m)

Deflection is a change in the shape of the beam in the $y$-direction due to the vertical loading applied to the beam or bar. Deformation in the beam can very easily be explained by the deflection of the beam from its position before experiencing loading. The deflection is measured from the initial neutral surface to the neutral position after deformation. The configuration assumed with the deformation of the neutral surface is known as the elastic curve of the beam [12].

The strain on the horizontal axis and stress on the vertical axis. The graph of the relationship between stress and strain is shown schematically (not scaled) for a steel specimen in Fig. 8 [13].

The load is evenly distributed with the point load, both of which have different deflection curves. In a uniformly distributed load, the slope that occurs at the closest part of the rod is greater than the slope of the point. This is because as long as the rod experiences a point load, it only occurs at a certain point [14].

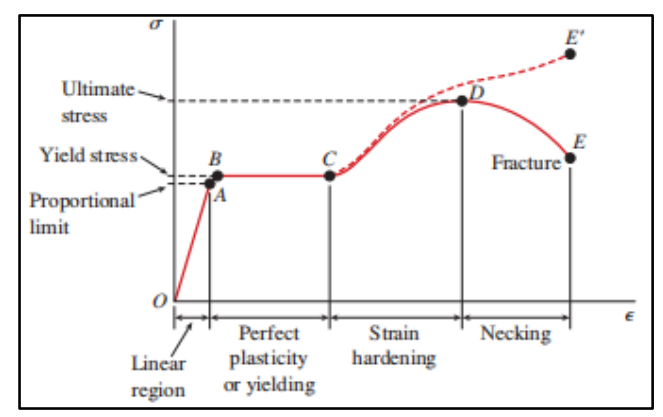

Figure 8. Stress-strain relationship diagram 


\section{Research Method}

The research was conducted by using a numerical method, by using General Cargo ships as the models. The ship original is equipped with two cargo hold, with inner bottom plate construction continuous from the left side to the starboard side without margin plate, As for the drawing of margin plates according to the 1984 rules of Nippon Kaiji Kyokai (NK) "Rules and Regulations For the Construction and Classification Of Ships" [4]. The bottom construction of the models was then modified by adding the margin plate to analyze the effect of the margin plate on the strength of the ship's construction. Modeling was carried out on ANSYS ${ }^{\mathrm{TM}}$ software from the engine room divider to the cargo hold bulkhead (one load room) with a load room length of 30.1 meters.

\section{Result and Discussion}

\subsection{Calculations ship transverse strength}

The load that used in the Ansys ${ }^{\mathrm{TM}}$ model is based on the calculation of deck load, side load, and bottom load obtained from the BKI Rules for Volume 1, 2016 Edition [15]. Then the point of review on both models must be the same, namely the meeting between the bilge plate and side plate. The ship model without margin plate is abbreviated as TMP while the ship model with margin plate is abbreviated as DMP.

\section{a) Analysis of transverse structure of the ship}

\section{- Displacement}

Some parts of the structure being modeled will experience displacement when a load acts on them. The maximum displacement occurs in the deck plate. In the model without a margin plate (node 289189) there is a deflection with a maximum value of $3,3365 \mathrm{~mm}$ while in the ship model with a margin plate (node 198637) there is a deflection with a maximum value of $3.40964 \mathrm{~mm}$ which can be seen in Fig. 9.

\section{- Stress}

Based on the results of the comparative analysis of transverse strengths on ships with and without margin plates. The stress that occurs in the model without a margin plate at node 282746 is in $100 \%$ condition, namely $8.4739 \mathrm{~N} / \mathrm{mm}^{2}$, while the model with a margin plate at node 147724 is in $100 \%$ condition which is $9.6242 \mathrm{~N} /$ $\mathrm{mm}^{2}$. Then carried out variations in the load including deck load, side load and bottom load to obtain the resulting stress ratio curve can be seen in Fig. 8 and Fig. 9.

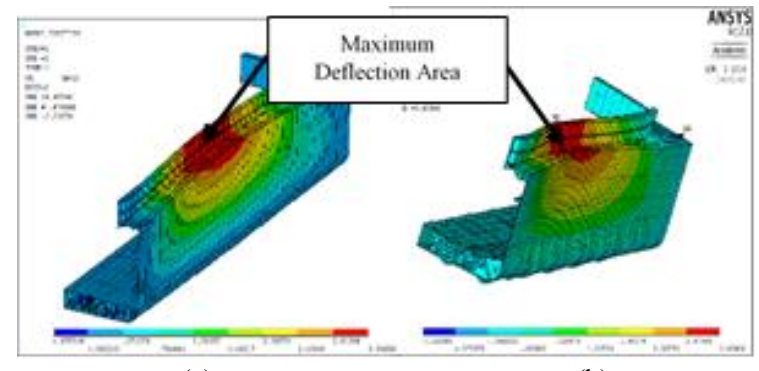

(a)

(b)

\subsection{Variations in the transverse force of the ship}

Loading variations are carried out to get the tendency of the ship structure's response to each load change. In the variation of the load, the transverse strength of this ship includes deck load $\left(\mathrm{P}_{\mathrm{D}}\right)$, side load $\left(\mathrm{P}_{\mathrm{S}}\right)$, and bottom load $\left(\mathrm{P}_{\mathrm{B}}\right)$, which are used as reference loads and assumed to be $100 \%$ load. By giving each load increase of $0.2 \mathrm{x}$ the maximum load $(100 \%)$ which is calculated using the BKI Rules. In the variation of deck load with constant side load and bottom load $100 \%$ the maximum load while the sideload variation with constant deck load and bottom load while in the variation of the bottom load with constant deck load and sideload are also varied as well as the deck, side, and bottom loads. The result of the relation between strees and variation of loads was shown in Fig. 10 to Fig. 15.

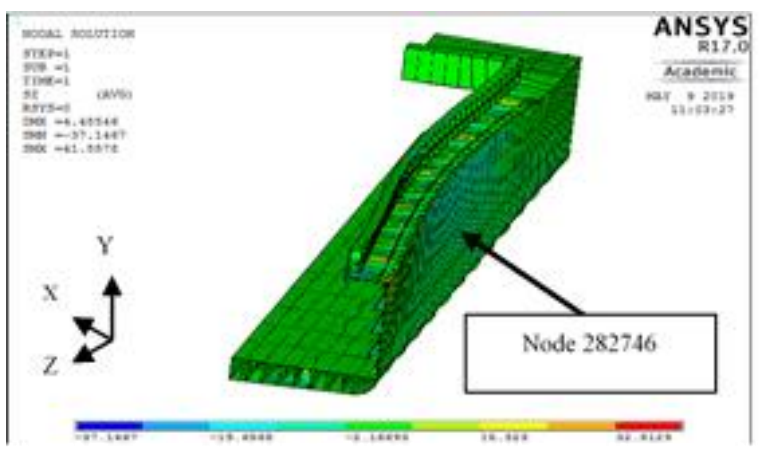

Figure 10. Viewpoints for Stress in Models without Margin Plate

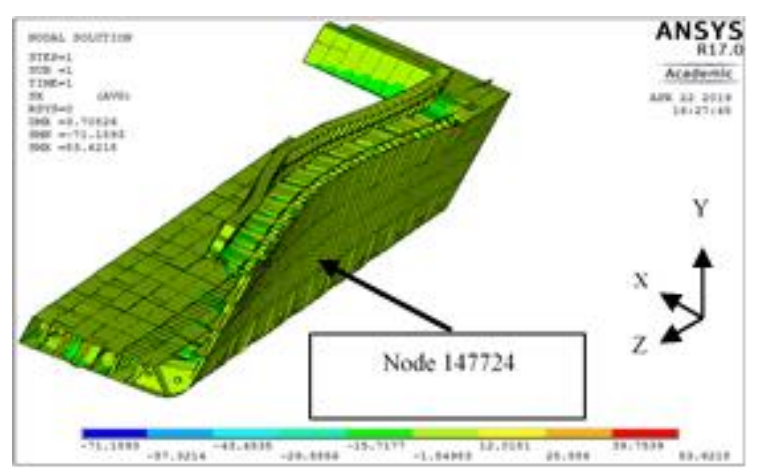

Figure 11. Viewpoints for Stress in Models with Margin Plate

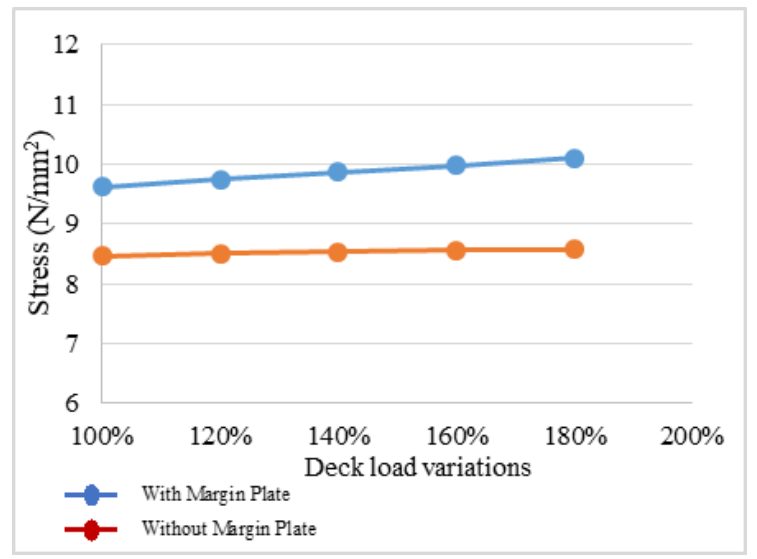

Figure 12. The relation between deck load variations and stress on models with and without margin plate

Figure 9. Displascement in the $\mathrm{x}$ direction for the model without margin plate (a) and with margin plate (b) 


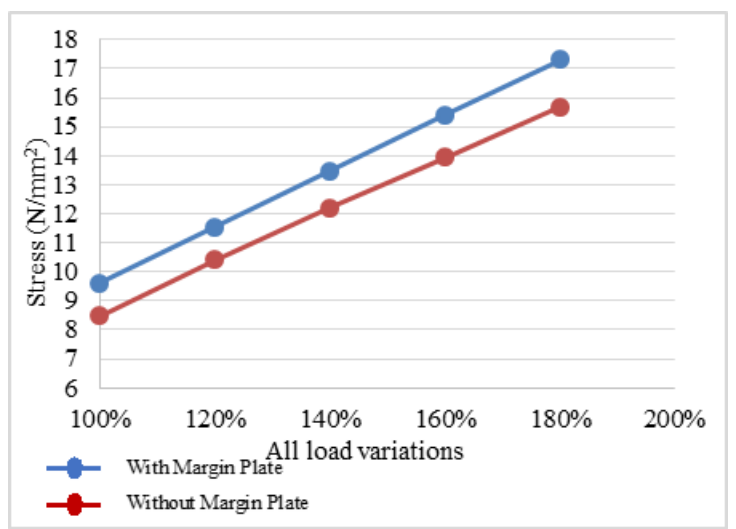

Figure 13. The relation between side load variations and stresses on models with and without margin plate

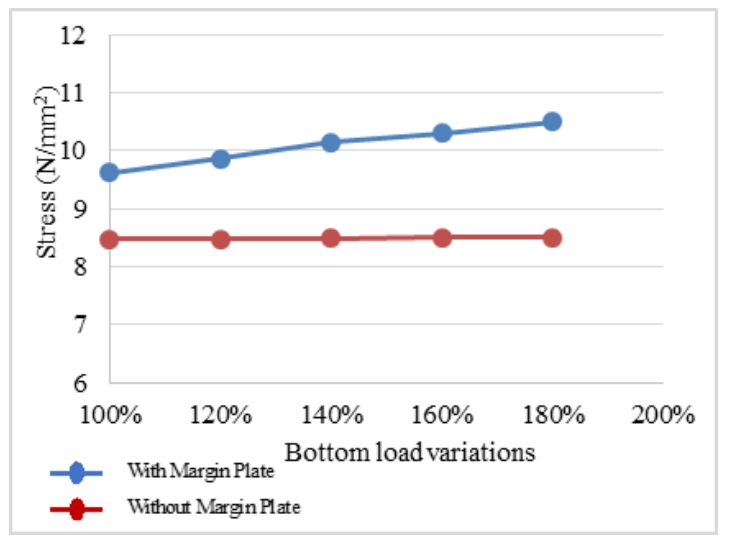

Figure 14. The relation between bottom load variations and stresses on models with and without margin plate

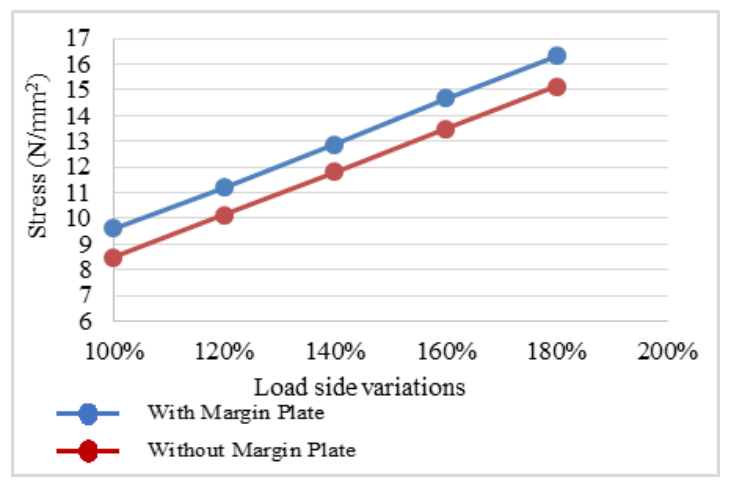

Figure 15. The relation between all load variations and stresses on models with and without margin plate

\subsection{Calculations ship longitudinal strength}

The ship loading installed in the Ansys model is based on the calculation of the external moment which is then defined in force (F). This style will later be installed on the Ansys model. Then for the longitudinal strength of the ship, the MPC (Multi-Point Constraint) method is used where one of the nodes at the and of the model is clamped and the other end node is given a moment.

a) Variation of the vertical bending moment the ship's longitudinal load

Based on the results of calculations on the BKI rules, the results of the variation of the vertical bending moment in the hogging conditions are $8.14 \times 10^{9} \mathrm{Nmm}$ and the sagging conditions are $-9.17 \times 10^{9} \mathrm{Nmm}$. Then vary every multiple of $0.2 \times$ maximum vertical bending moment as shown in Table 1.

Based on the results of the analysis on Ansys software, the stress value is $100 \% \mathrm{x}$ moment max. in the hogging condition it is $8.14 \times 10^{9} \mathrm{Nmm}$ and the sagging condition is $-9.17 \times 10^{9} \mathrm{Nmm}$ then it was varied as shown in Table 2 and Table 3 . Then the point of review of the two models is in the bottom area (the meeting between the bottom plate and the bilge plate) and the deck (the meeting between the side plate and the deck plate).

Table 1. Variation of vertical bending moment

\begin{tabular}{ccc}
\hline & \multicolumn{2}{c}{ Vertical Bending Moment } \\
\cline { 2 - 3 } Load variations & $\begin{array}{c}\text { Hogging } \\
\text { Conditions } \\
(\mathbf{N m m})\end{array}$ & $\begin{array}{c}\text { Sagging } \\
\text { Conditions } \\
(\mathbf{N m m})\end{array}$ \\
\hline $\begin{array}{c}100 \% \times \text { Moment } \\
\text { Max. }\end{array}$ & $8.14 \times 10^{9}$ & $-9.17 \times 10^{9}$ \\
$\begin{array}{c}120 \% \times \text { Moment } \\
\text { Max . }\end{array}$ & $9.77 \times 10^{9}$ & $-1.10 \times 10^{10}$ \\
$\begin{array}{c}140 \% \times \text { Moment } \\
\text { Max. }\end{array}$ & $1.14 \times 10^{10}$ & $-1.28 \times 10^{10}$ \\
$160 \% \times$ Moment \\
$\begin{array}{c}\text { Max. } \\
180 \% \times \text { Moment } \\
\text { Max. }\end{array}$ & $1.30 \times 10^{10}$ & $-1.47 \times 10^{10}$ \\
\hline
\end{tabular}

Table 2. Variation of vertical bending moment in hogging conditions

\begin{tabular}{|c|c|c|c|c|c|}
\hline \multirow[b]{2}{*}{$\begin{array}{c}\text { Load } \\
\text { Variation }\end{array}$} & \multirow[b]{2}{*}{$\begin{array}{c}\text { Hogging } \\
\text { Moment } \\
(\mathrm{Nmm})\end{array}$} & \multicolumn{2}{|c|}{$\begin{array}{c}\text { With } \\
\text { Margin Plate } \\
\end{array}$} & \multicolumn{2}{|c|}{$\begin{array}{c}\text { Without } \\
\text { Margin Plate }\end{array}$} \\
\hline & & $\begin{array}{c}\text { Stress on } \\
\text { Deck } \\
\left(\mathrm{N} / \mathbf{m m}^{2}\right) \\
\text { node: } \\
690200\end{array}$ & $\begin{array}{c}\text { Stress on } \\
\text { Bottom } \\
\left(\mathrm{N} / \mathbf{m m}^{2}\right) \\
\text { node: } \\
686946\end{array}$ & $\begin{array}{c}\text { Stress on } \\
\text { Deck } \\
\left(\mathrm{N} / \mathbf{m m}^{2}\right) \\
\text { node: } \\
701345\end{array}$ & $\begin{array}{c}\text { Stress on } \\
\text { Bottom } \\
\left(\mathrm{N} / \mathrm{mm}^{2}\right) \\
\text { node: } \\
\mathbf{6 6 1 6 6 2}\end{array}$ \\
\hline $\begin{array}{c}100 \% \mathrm{x} \\
\text { Moment } \\
\text { Max. }\end{array}$ & $\begin{array}{c}8.14 \mathrm{x} \\
10^{9}\end{array}$ & 11.38 & -20.585 & 16.705 & -11.045 \\
\hline $\begin{array}{c}120 \% \mathrm{x} \\
\text { Moment } \\
\text { Max. }\end{array}$ & $\begin{array}{c}9.77 \mathrm{x} \\
10^{9}\end{array}$ & 13.659 & -24.707 & 20.050 & -13.257 \\
\hline $\begin{array}{c}140 \% \mathrm{x} \\
\text { Moment } \\
\text { Max. }\end{array}$ & $\begin{array}{c}1.14 \mathrm{x} \\
10^{10}\end{array}$ & 15.538 & -28.829 & 23.395 & -15.469 \\
\hline $\begin{array}{c}160 \% \mathrm{x} \\
\text { Moment } \\
\text { Max. }\end{array}$ & $\begin{array}{c}1.30 \mathrm{x} \\
10^{10}\end{array}$ & 18.175 & -32.876 & 26.679 & -17.640 \\
\hline $\begin{array}{c}180 \% \mathrm{x} \\
\text { Moment } \\
\text { Max. }\end{array}$ & $\begin{array}{c}1.47 \mathrm{x} \\
10^{10}\end{array}$ & 20.551 & -37.174 & 30.168 & -19.947 \\
\hline
\end{tabular}

Table 3. Variation of vertical bending moment in sagging conditions

\begin{tabular}{|c|c|c|c|c|c|c|}
\hline \multirow[b]{2}{*}{$\begin{array}{c}\text { Load } \\
\text { Variation }\end{array}$} & \multirow{2}{*}{\multicolumn{2}{|c|}{$\begin{array}{c}\text { Hogging } \\
\text { Moment } \\
\text { (Nmm) }\end{array}$}} & \multicolumn{2}{|c|}{$\begin{array}{c}\text { With } \\
\text { Margin Plate }\end{array}$} & \multicolumn{2}{|c|}{$\begin{array}{c}\text { Without } \\
\text { Margin Plate }\end{array}$} \\
\hline & & & $\begin{array}{c}\text { Stress on } \\
\text { Deck } \\
\left(\mathrm{N} / \mathbf{m m}^{2}\right) \\
\text { node: } \\
690200\end{array}$ & $\begin{array}{c}\text { Stress on } \\
\text { Bottom } \\
\left(\mathrm{N} / \mathbf{m m}^{2}\right) \\
\text { node: } \\
686946\end{array}$ & $\begin{array}{c}\text { Stress on } \\
\text { Deck } \\
\left(\mathrm{N} / \mathbf{m m}^{2}\right) \\
\text { node: } \\
701345\end{array}$ & $\begin{array}{c}\text { Stress on } \\
\text { Bottom } \\
\left(\mathrm{N} / \mathbf{m m}^{2}\right) \\
\text { node: } \\
661662\end{array}$ \\
\hline $\begin{array}{c}100 \% \mathrm{x} \\
\text { Moment } \\
\text { Max. }\end{array}$ & $\begin{array}{c}-9.17 \times \\
10^{9}\end{array}$ & & -12.82 & 23.189 & -18.819 & 12.44 \\
\hline $\begin{array}{c}120 \% \mathrm{x} \\
\text { Moment } \\
\text { Max. }\end{array}$ & $\begin{array}{l}-1.10 \\
10^{10}\end{array}$ & $\mathrm{x}$ & -15.379 & 27.817 & -22.574 & 14.93 \\
\hline $\begin{array}{c}140 \% \mathrm{x} \\
\text { Moment } \\
\text { Max. }\end{array}$ & $\begin{array}{l}-1.28 \\
10^{10}\end{array}$ & $\mathrm{x}$ & -17.895 & 32.369 & -26.268 & 17.37 \\
\hline $\begin{array}{c}160 \% \mathrm{x} \\
\text { Moment } \\
\text { Max. }\end{array}$ & $\begin{array}{l}-1.47 \\
10^{10}\end{array}$ & $\mathrm{x}$ & -20.551 & 37.134 & -30.168 & 19.92 \\
\hline $\begin{array}{c}180 \% \mathrm{x} \\
\text { Moment } \\
\text { Max. }\end{array}$ & $\begin{array}{l}-1.65 \times \\
10^{10}\end{array}$ & & -23.068 & 41.726 & -33.862 & 22.39 \\
\hline
\end{tabular}


b) Displacement and Stress in Deck Plates and Bottom Plates on Ship Models with and without margin plate

- Sagging conditions

- Displacement

Some parts of the structure being modeled will experience a displacement when a load acts on them. and after analysis on ANSYS ${ }^{\mathrm{TM}}$ software, as shown in Fig. 16, the deflection of the ship model without plate margin on the deck plate at node 701345 is $-2.4112 \mathrm{~mm}$ and on the bottom plate at node 661662 which is $1.9221 \mathrm{~N} / \mathrm{mm}^{2}$.

The deflection results on the ship model with the plate margin obtained on the deck plate at node 690200, namely $-1.872 \mathrm{~mm}$ and on the bottom plate at node 686946 which is $2.6132 \mathrm{~mm}$, as shown in Fig. 17.

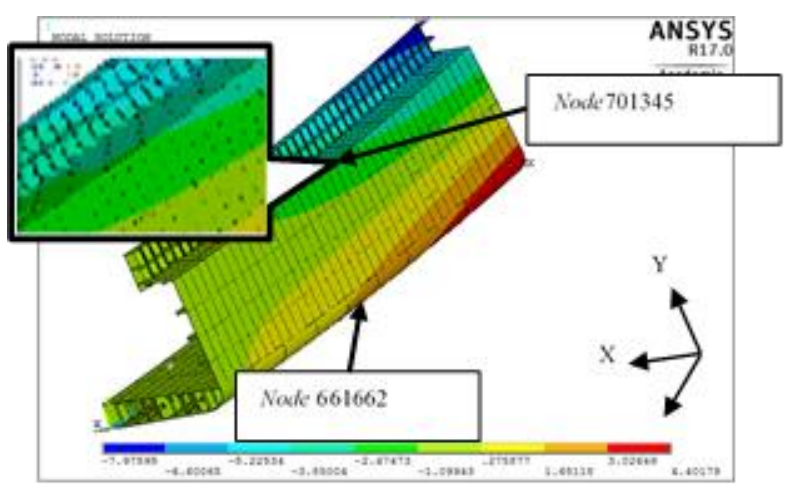

Figure 16. Respond and displacement z-direction in the sagging conditions on the ship model without margin plates on the deck plate and the bottom plate

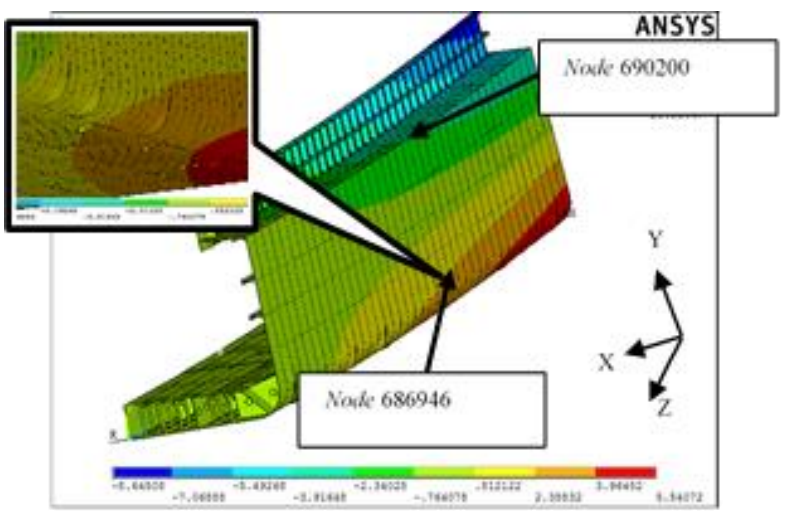

Figure 17. Respond and displacement in the z-axis direction of sagging conditions on the ship model with margin plates on the deck plate and the bottom plate

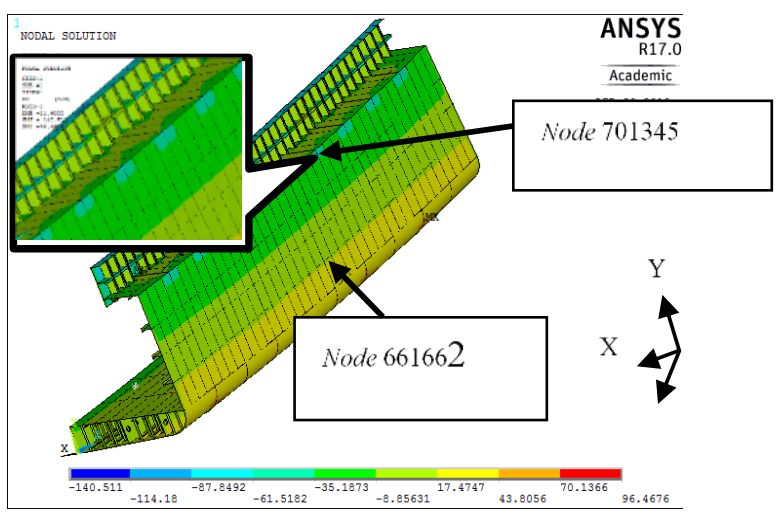

Figure 18. Respond and stress distribution in the z-axis direction of sagging conditions on a ship model without plate margins on the deck plate and bottom plate

\section{- $\quad$ Stress}

Some parts of the structure being modeled will experience stress when a load acts on them. The stress obtained on the ship model without a margin plate on the deck plate at node 701345 is $-18.819 \mathrm{~N} / \mathrm{mm}^{2}$ and on the bottom plate at node 661662 which is $12.443 \mathrm{~N} / \mathrm{mm}^{2}$. as shown in Fig. 18.

The stress results on the ship model with the margin plate obtained on the deck plate at node 690200 is -12.82 $\mathrm{N} / \mathrm{mm}^{2}$ and on the bottom plate at node 686946 which is $23.189 \mathrm{~N} / \mathrm{mm}^{2}$, as shown in Fig. 19.

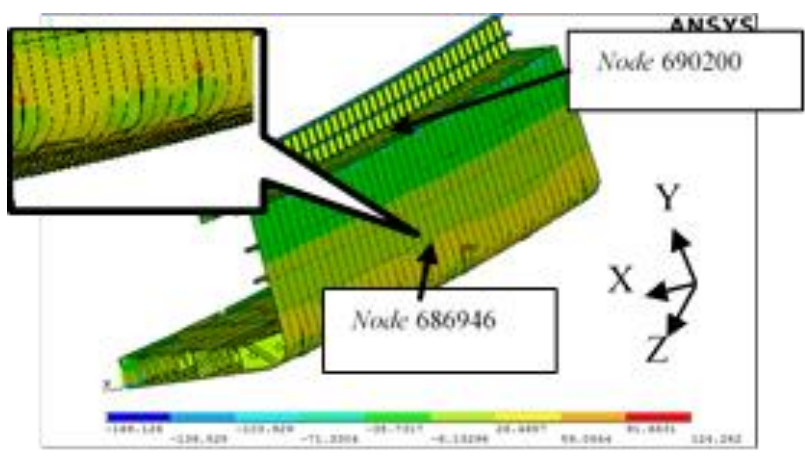

Figure 19. Respond and stress distribution in the $\mathrm{z}$-axis direction of sagging conditions on a ship model with plate margins on the deck plate and bottom plate

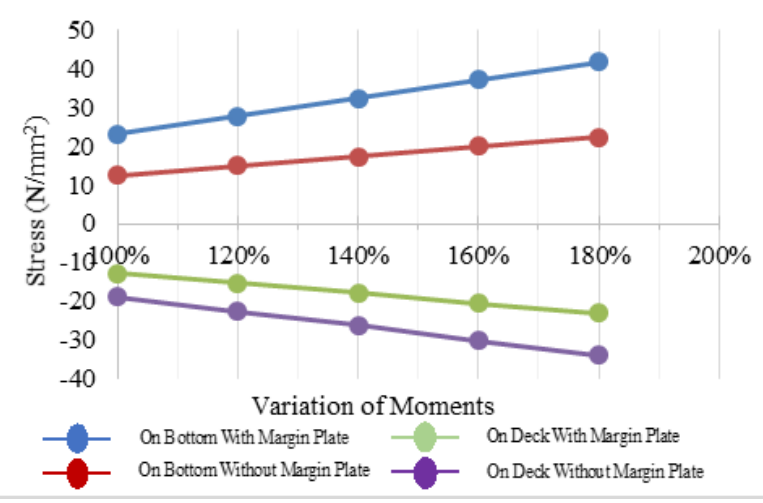

Figure 20. The relation between variation of bending moment and the stress in the sagging condition

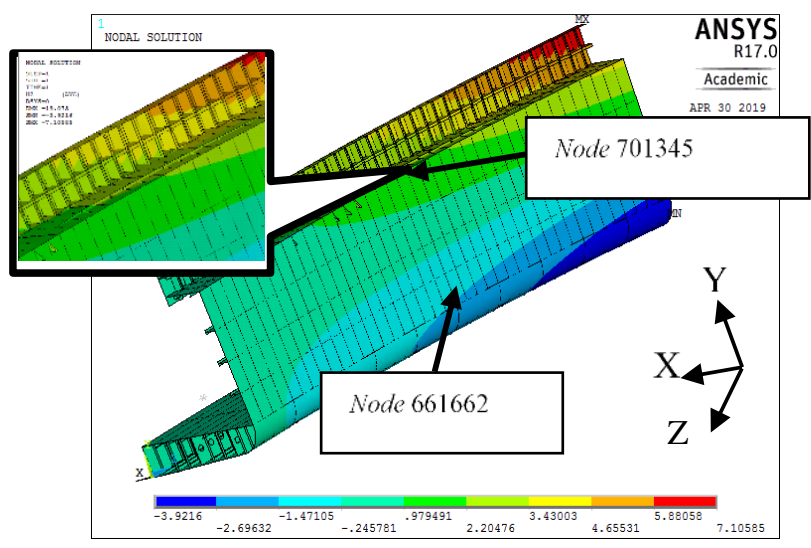

Figure 21. Respond and stress distribution in the $\mathrm{z}$-axis direction of hogging conditions on a ship model without plate margins on the deck plate and bottom plate 


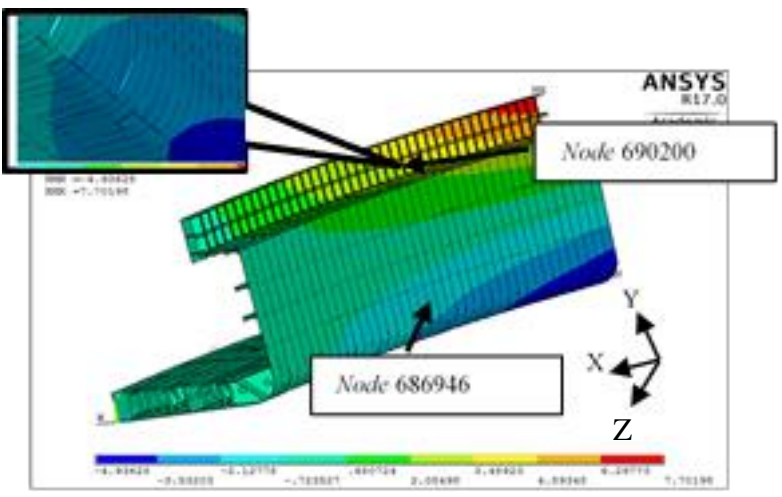

Figure 22. Respond and stress distribution in the $\mathrm{z}$-axis direction of hogging conditions on a ship model with plate margins on the deck plate and bottom plate

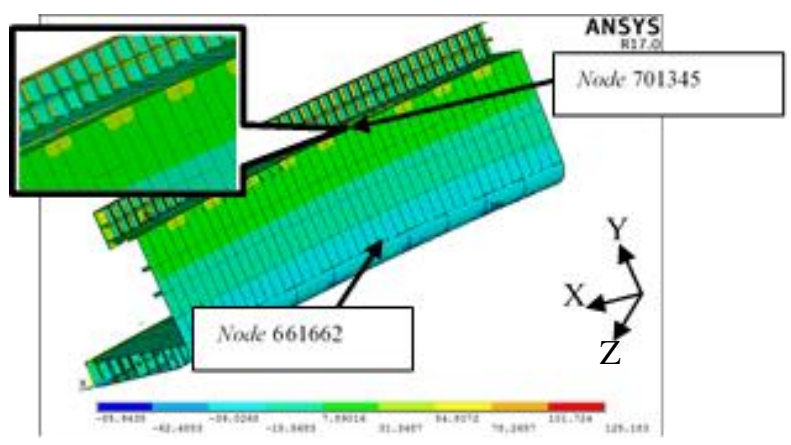

Figure 23. Respond and stress distribution in the z-axis direction of hogging conditions on a ship model without plate margins on the deck plate and bottom plate

- Hogging Conditions

- Displacement

Displacement in the ship model without plate margin on the deck plate at node 701345 is $2.1220 \mathrm{~mm}$ and on the bottom plate at node 661662 which is $-1.7233 \mathrm{~mm}$ can be seen in Fig. 21 and Fig. 22.

The deflection results on the ship model with the margin plate obtained on the deck plate at node 690200 is $1.6224 \mathrm{~mm}$ and on the bottom plate at node 686946 which is $-2.3421 \mathrm{~mm}$.

\section{- Stress}

Some parts of the structure being modeled will experience stress (stress) when a load acts on them. The stress obtained on the ship model without a margin plate on the deck plate (the meeting between the deck plate and the side plate) at node 701345 is $16.705 \mathrm{~N} / \mathrm{mm}^{2}$ and on the bottom plate (the meeting between the bottom plate and the bilge plate) at node 661662 is $-11.045 \mathrm{~N} / \mathrm{mm}^{2}$, as shown in Fig. 23.

The stress results on the ship model with margin plate obtained on the deck plate at node 690200 are 11.38 $\mathrm{N} / \mathrm{mm}^{2}$ and on the bottom plate at node 686946 which is $20.585 \mathrm{~N} / \mathrm{mm}^{2}$, as shown in Fig. 24.

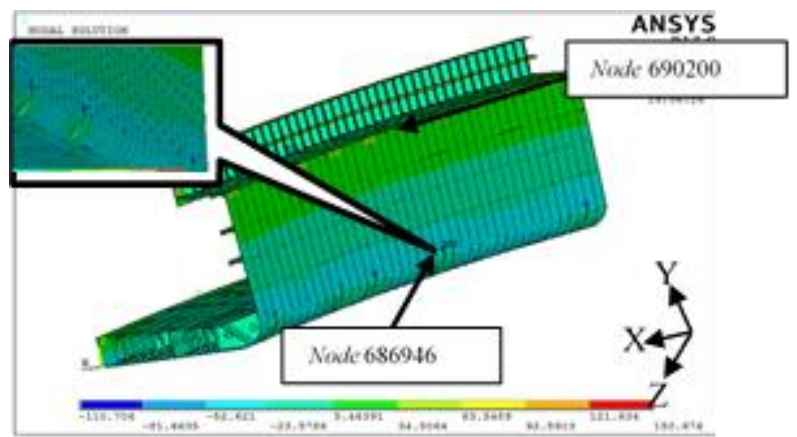

Figure 24. Respond and stress distribution in the z-axis direction of hogging conditions on a ship model with plate margins on the deck plate and bottom plate

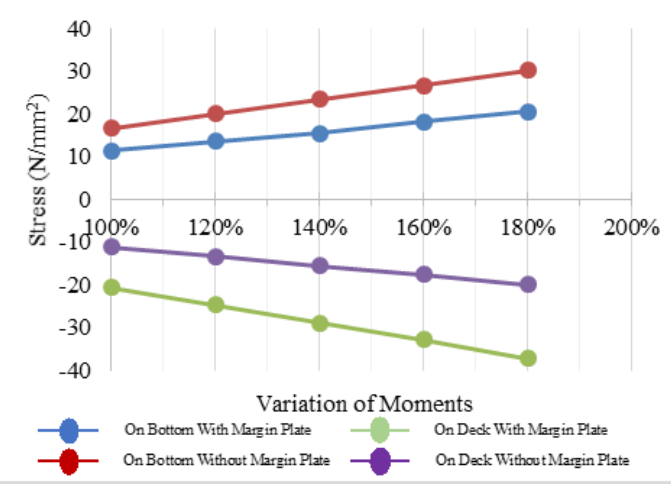

Figure 25. The relation between the increase in vertical bending moment and the working stress in hogging conditions

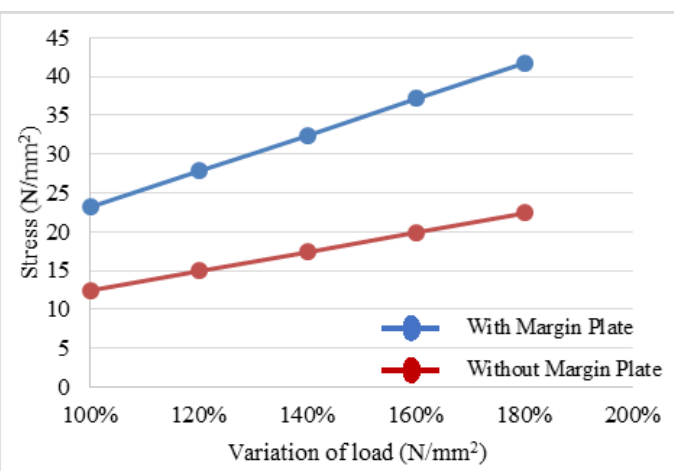

(a) Sagging condition

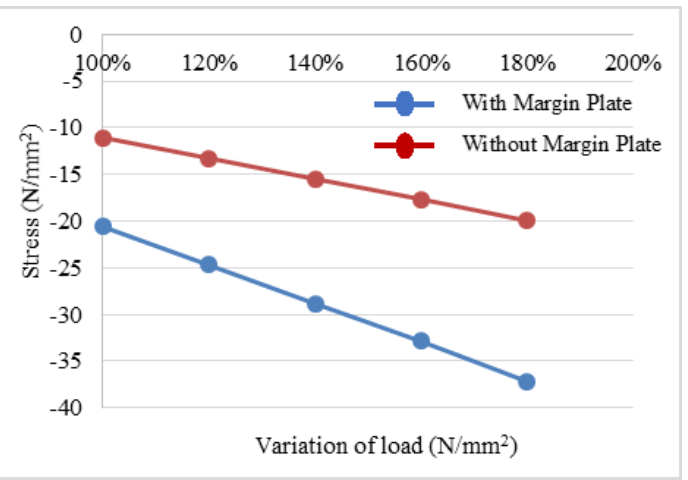

(b) Hogging condition

Figure 26. Relation between stress and variations of longitudinal loads at the meeting of the bottom plate with the bilge plate in sagging (a) and the hogging (b) conditions 


\section{Conclusions}

The stress generated on a ship model without using a margin plate is better able to withstand transverse loads when compared to a ship model using a margin plate.

a) The amount of difference in high stress due to the influence of the load is an average of $15.82 \%$. Then the difference in stress on the deck load is $13.49 \%$ on average, while the sideload is $8.74 \%$ on average.

b) The amount of stress difference generated at the vertical bending moment for the sagging and hogging conditions in the bottom area is $46.34 \%$. The results of the stress on a ship model without using a margin plate are better able to withstand longitudinal loads when compared to a ship model using a margin plate.

\section{References}

[1] M. D. Rosyid and D. Setyawan, Ship Structure Strength. Jakarta: Pradya Paramita, 2000. [in Bahasa]

[2] E. Hirohiko, Illustration Of Hull Structures. Japan, 2007.

[3] Rosmani, Ship Construction I Midship Section. Makassar, 2000. [in Bahasa]

[4] Nippon Kaiji Kyokai, Rules and Regulations for the Construction and Classification of Ships. Japan, 1984.

[5] N. Barabanov, Structural Design of Sea-Going Ships. Moscow: Peace Publisher, 1960.

[6] I. K. Djaya, Steel Ship Construction Engineering. Book Center of the Ministry of National Education, 2008. [in Bahasa]

[7] Hughes, F. Owen, and J. K. Paik, Ship Construction Analysis and Design. New Jersey: The Society of Naval Architecture and Marine Engineers, 2010.

[8] M. Shama, "Buckling of Ship Structures," Alexandria University, 2013.

[9] Y. Susatio, Finite Element Method. Surabaya: ITS, 2004. [in Bahasa]

[10] D. B. Marghitu, Mechanical Engineer's Handbook. Academic Press, 2001.

[11] A. Setiawan, Steel Structure Planning. Jakarta: Erlangga, 2002. [in Bahasa]

[12] L. D. Schodek, Structure. Bandung: Rafika Aditama, 1998. [in Bahasa]

[13] J. M. Gere and B. J. Goodno, Mechanics of Materials Seventh Edition, 7th Ed. Cengage Learning, 2009.

[14] B. Hariandja, Mekanika Teknik: Statics in Analysis of Frame Structure. Jakarta: Erlangga, 1996. [in Bahasa]

[15] Biro Klasifikasi Indonesia, Domestic Hull Guidelines Volume 1. Jakarta, 2016. 